\title{
Adverse effect of inhalational anesthetics on the developing brain
}

\author{
Mike Wang ${ }^{1}$, John H Zhang ${ }^{2}$ and Richard L Applegate I $^{1^{*}}$
}

\begin{abstract}
We did a PubMed search and summarized studies on the potential adverse effect of anesthetics especially neurotoxicity in the developing brain, so named anesthesia-induced developmental neurotoxicity. Even though many experimental studies using animal models indicated some adverse effect of anesthetics, more evidence is needed before a recommendation can be made to change the way those anesthetics are used in the pediatric population. Two large clinical trials are underway and may provide insight to the potential human neurotoxic effect of anesthetics.
\end{abstract}

Keywords: Anesthetics, Developing brain, Neurotoxicity

\section{Introduction}

Each year in the United States, approximately three million infants and children receive anesthesia for surgical procedures, with many more receiving anesthesia for imaging studies or dental procedures [1]. It was previously thought that anesthetic drugs caused short term sedation without any long term sequelae in the developing brain. This notion has now come into question, with numerous animal studies showing that general anesthetics have neurodegenerative effects on the developing brain, causing anesthesia-induced developmental neurotoxicity (AIDN).

In 2000, Ikonomidou et al showed that ethanol, acting by a dual mechanism [blockade of $N$-methyl-D-aspartate (NMDA) receptor and excessive activation of $\gamma$ aminobutyric acid $\left(\mathrm{GABA}_{\mathrm{A}}\right)$ receptors], triggers diffuse neuroapoptosis in the developing rat brain, with the peak of toxicity coinciding with the period of synaptogenesis [2]. These results raised questions of whether general anesthesia can also cause neuroapoptosis, since like ethanol, most anesthetic medications work as NMDA receptor antagonists or $\mathrm{GABA}_{\mathrm{A}}$ receptor agonists.

Subsequently in 2003, Jevtovic-Todorovic et al demonstrated that a one time exposure to a common anesthetic cocktail of isoflurane, midazolam, and nitrous oxide, also caused neuroapoptosis in the developing rat brain during

\footnotetext{
* Correspondence: rapplegate@llu.edu

'Department of Anesthesiology, Loma Linda University School of Medicine, Loma Linda, CA 92350, USA

Full list of author information is available at the end of the article
}

the period of synaptogenesis [3]. This one time anesthetic exposure was also found to cause long term neurocognitive dysfunction that continued from adolescence into adulthood. These results in an animal model again raised questions of whether a routine anesthetic exposure could cause AIDN in neonates, infants, or even very young children.

These findings caused much debate within the pediatric anesthesia community at the time they were published. Many counter points were raised that highlighted the differences between anesthetic exposure in rats and humans [4]. It was argued that there is less control over environmental conditions when anesthesia is performed on rats, with hypoxemia, hypercarbia, and hypoglycemia being potential confounding variables in lab experimentation. When subsequent publications in animal models showed evidence of AIDN despite controlling for physiological variables [5,6], the focus of research shifted to determine what ramifications these results might have on the clinical practice of pediatric anesthesia. In March of 2007 the US Food and Drug Administration held an advisory meeting to review the data on AIDN and decide whether a change in pediatric anesthesia practice was warranted [7].

Though the advisory meeting did not recommend making any formal changes to current pediatric anesthesia practices, it did urge the anesthesia community to conduct studies to determine if AIDN can occur in children. There are currently two large prospective multi-center trials being conducted. The Pediatric Anesthesia NeuroDevelopment Assessment (PANDA Study) [8] is looking at children 
exposed to a single general anesthetic before age three compared to a control sibling who has not had anesthesia. The second trial is the GAS study (NCT00756600), comparing spinal or general anesthesia for inguinal hernia repair in newborns. Due to the nature of these trials, it will still be a number of years before any meaningful data on neurodevelopmental outcomes will be published. Thus it is prudent to continue conducting and reviewing new developments in animal research on AIDN.

\section{Methods}

A PubMed search was done in April 2013 with search terms in Table 1. Intravenous anesthetic agents were included as search terms to obtain a broader range of articles, even though they are not covered in this review. In addition to this database search, reference lists of relevant articles were reviewed for additional publications of interest.

\section{Review}

The PubMed search resulted in 347 articles, of which 84 articles were identified as pertaining to the topic. Out of this group of articles, a subset of 44 articles was identified as being relevant to inhalational anesthetics and their effects on the developing animal brain.

\section{Inhalational anesthetics}

In the pediatric population, inhalational anesthetics are by far the most common drugs used for the induction and maintenance of general anesthesia. Among the articles reviewed, inhalational anesthetics have been shown to be neurotoxic in the developing brain of all animal models tested to date, which include rats, mice, guinea pigs, piglets, and rhesus monkeys [3,6,9-13]. Mechanistically speaking, inhalational anesthetics cause general anesthesia predominately as $\mathrm{GABA}_{\mathrm{A}}$ agonists [14] and NMDA receptor antagonists [15], though there are varying degrees of affinity for these receptors among differing anesthetic medications. These differences might give insight into why certain inhalational anesthetics cause more neurodegeneration than others.

\section{Isoflurane}

Since 2003, isoflurane has been the most extensively studied inhalational anesthetic. In an attempt to create clinically relevant animal models, a number of studies have looked into the minimum alveolar concentration (MAC) of isoflurane in newborn rodents. It has been established that the MAC of 2.5 month old rats does not change depending on the length of anesthesia if physiologic parameters are kept constant [16]. More recently it was shown that the MAC of isoflurane in nine day old rats (P9) is $2.34 \%$ [17], which was the basis for isoflurane concentrations used in studies of developmental neurotoxicity. The notion of a static MAC value has now come into question for neonatal rodents.

Stratmann et al in a study on P7 rats found that MAC requirements decreased from $1 \mathrm{~h}$ to $4 \mathrm{~h}$ into an anesthetic [18]. With direct sampling of brain partial pressures of isoflurane, this decrease in MAC was found to come about in P7 rats even after full equilibration with inspiratory gas concentration, suggesting a pharmacodynamic process that occurs in $\mathrm{P} 7$ rats but not $\mathrm{P} 60$ rats. In $\mathrm{P} 7$ rats median MAC was $2.75 \%$ at $1 \mathrm{~h}$ and $1.3 \%$ at $4 \mathrm{~h}$ of isoflurane anesthesia, while in P60 rats median MAC was $1.65 \%$ at $1 \mathrm{~h}$ and $1.5 \%$ at $4 \mathrm{~h}$. Similar decreases in MAC with increased duration of anesthesia have also been documented in neonatal mice, using isoflurane, sevoflurane or desflurane as a sole anesthetic agent [19]. More research is needed to see if this phenomenon of decreasing MAC requirements in neonatal animal models has any bearing on clinical practice.

In light of this new finding, studies on AIDN in animal models can be reexamined in regards to dosages chosen. In P7 rats, a combination of $0.75 \%$ isoflurane with $9 \mathrm{mg} / \mathrm{kg}$ midazolam and $75 \%$ nitrous oxide for $6 \mathrm{~h}$ caused widespread AIDN followed by learning impairment at P32 that lasted until adulthood at P131 [3]. However, this anesthetic exposure did not have any effects on overall growth, sensory motor ability, spontaneous locomotion, or attention. Using a MAC of 2.21 atm for nitrous oxide in SpragueDawley rats [20], the combined MAC of the anesthetic gases at $1 \mathrm{~h}$ exposure totaled 0.61 MAC, and at $4 \mathrm{~h}$ exposure totaled $0.92 \mathrm{MAC}$. These MAC levels are similar to those used in everyday clinical practice.

The same combination of anesthetic agents exposed to rats aged P1 to P14 for $6 \mathrm{~h}$, again showed evidence of AIDN in all age groups tested, with the height of toxicity at age P7, coinciding with the peak of synaptogenesis $[6,21]$.

Table 1 Search terms used in review article database search

\begin{tabular}{ll}
\hline Database & Search terms \\
\hline PubMed & $\begin{array}{l}\text { Brain (newborn or infant or child or neonate or neonatal or animals, newborn) and } \\
\text { (neurodegeneration or apoptosis or toxicity or neurocognitive impairment or developmental } \\
\text { impairment or developmental disabilities, or learning disorders) and (isoflurane or desflurane or } \\
\text { sevoflurane or propofol or etomidate or ketamine or lorazepam or diazepam or midazolam or } \\
\text { pentobarbital or phenobarbital or anesthesia, IV or anesthesia, inhalation or anesthesia). } \\
\text { In PubMed, terms are searched as subject headings and keywords simultaneously. } \\
\text { Articles were limited to those printed or translated into English. }\end{array}$ \\
\hline
\end{tabular}


Similar studies in guinea pigs [10], piglets [12], and rhesus monkeys [11] all showed age dependent vulnerability to AIDN, demonstrating that AIDN exists in animals with longer periods of synaptogensis like humans. Rodent in vitro studies have also shown comparable results [5,22]. A similar time period of peak synaptogenesis in humans is thought to range from the third trimester of gestation to several years after birth [21]. It remains to be seen whether AIDN occurs in humans, and if it does, the exact age of maximal vulnerability to anesthetic agents.

Other animal studies that have shown declines in neurocognitive function after a single isoflurane exposure include an experiment on P7 rats exposed to $0.75 \%$ isoflurane and $70 \%$ nitrous oxide for $6 \mathrm{~h}$ [23]. These rats showed long term memory impairment at P47 when assessed with trace fear conditioning. In the same study, pretreatment with $70 \%$ xenon for $2 \mathrm{~h}$ prior to isoflurane and nitrous oxide exposure was able to attenuate AIDN. Xenon pretreatment rats did not differ compared to control rats when longterm memory was assessed at P47. In a follow up study, the same anesthetic regimen was exposed to P7 rats, causing AIDN and long-term memory impairment at P47 [24]. A single $0.3 \mathrm{~cm}$ surgical incision made to the left hind paw at the start of the anesthetic exposure increased neuroapoptosis rates by approximately $60 \%$ compared to anesthesia alone, and statistically increased the degree of long term memory dysfunction when compared to anesthesia alone at P47. However, although P7 mice exposed to isoflurane had apoptotic cell death early after exposure, no differences in adult cell density, learning or activity was found in isoflurane-exposed compared to controls [25].

Of interest is an article published April 2013, in which isoflurane was shown to be neuroprotective against AIDN. In this study, hippocampal slice cultures of P7 rats were exposed to 1 or $2 \mathrm{MAC}$ of xenon, isoflurane, or sevoflurane [26]. All three anesthetics caused similar levels of AIDN in this in vitro study. Preconditioning with $1.4 \%$ isoflurane $(0.75 \% \mathrm{MAC})$ for $2 \mathrm{~h}$ attenuated neuroapoptosis to control levels. More research is needed to see if this neuroprotective effect of isoflurane can be shown to reverse AIDN induced neurocognitive disfunction in in vivo animal models.

\section{Sevoflurane}

Sevoflurane is the most commonly used inhalational anesthetic in the USA for pediatric surgical cases. Due to its minimal airway reactivity and low blood/gas partition coefficient, sevoflurane has quickly become the inhalational induction agent of choice in operating rooms nationwide. Despite being so commonplace in pediatric anesthesia practice, the number of sevoflurane specific AIDN studies is small in comparison to isoflurane. The studies that have been published on sevoflurane and AIDN suggest a similar neurotoxic effect when compared to isoflurane administration in animal models.

In 2008 Zhang et al published the data on sevoflurane and AIDN. The study consisted of P7 mice exposed to $2 \mathrm{~h}$ of $1.7 \%$ sevoflurane anesthesia, resulting in significant AIDN in the sevoflurane group as compared to control using activated capase- 3 analysis [27]. Recently published MAC data of $3.8 \%$ at $1 \mathrm{~h}$ and $3.3 \%$ at $3 \mathrm{~h}$ of sevoflurane exposure [18], suggests that the concentration of $1.7 \%$ sevoflurane correlates to $0.45-0.52 \mathrm{MAC}$, which is a subclinical dose. A subsequent study exposed P6 mice to 3\% sevoflurane for $6 \mathrm{~h}$, showing wide spread AIDN, long term memory deficit from 8 weeks to 14-17 weeks of age as assessed with contextual/cued fear testing, and abnormal social interaction at age of 18 weeks of age, showing that sevoflurane like isoflurane causes long lasting neurocognitive dysfunction after a one time exposure in an animal model [28]. In contrast, in a study that compared isoflurane to sevoflurane anesthesia exposure in P7 rats, although markers of apoptosis were greater after isoflurane, neither agent was associated with impaired learning or memory when tested 31 to 40 days after anesthesia exposure [29].

Various case reports [30] as well as several studies $[31,32]$ have demonstrated epileptiform electroencephalogram and seizure activity during induction with sevoflurane in humans, while other studies have not reported these results [33,34]. In 2010 Edwards et al reported that $40 \%$ of rats aged P4 to P8 developed distinct episodes of epileptic seizures during maintenance with $2.1 \%$ sevoflurane [35]. These seizure-like episodes were not found in P10 to P17 rats during maintenance of anesthesia. Emergence after $3 \mathrm{~h}$ of sevoflurane anesthesia caused some tonic/clonic seizures in P10 to P17 rats, but not P4 to P8 rats. Bumetanide pretreatment significantly decreased the seizure activity in $\mathrm{P} 4$ to $\mathrm{P} 8$ rats during maintenance anesthesia, but not P10 to P17 rats during emergence. The same study also showed that exposure of $\mathrm{P} 4$ rats to $2.1 \%$ sevoflurane for $6 \mathrm{~h}$ caused significant AIDN. This effect was attenuated and reduced to control levels by pretreatment with bumetanide 15 minutes prior to sevoflurane exposure.

Two novel approaches to neuroprotection against AIDN caused by sevoflurane were recently published. The first study exposed P6 mice to 3\% sevoflurane for $6 \mathrm{~h}$ with or without $1.3 \%$ hydrogen as part of the carrier gas [36]. The concentrations of hydrogen gas used in this study were low enough to avoid explosion $[37,38]$. The mice exposed to sevoflurane alone showed significant increases in neuroapoptosis. Neurocognitive testing showed no different in general behavior or short term memory at 12 weeks of age, but did demonstrate a deficit in long term memory at 13 weeks of age. Coadministration of hydrogen gas during the sevoflurane anesthetic significantly reduced the extent of neuroapoptosis, and suppressed the impairment in 
long-term memory seen in mice exposed to sevoflurane alone. Free oxygen radical scavenging, one proposed effect of hydrogen gas administration, prevented cognitive decline in P7 rats exposed to general anesthesia [39]. The second study tested the effect of environmental enrichment on AIDN. Environmental enrichment has been shown to increase learning and memory after traumatic brain injury [40-42]. Pregnant mice at gestational day 14 (G14) were exposed to $2.5 \%$ sevoflurane for $2 \mathrm{~h}$, which in turn caused significant increases in neuroapoptosis in fetal mice [43]. Offspring mice were delivered at G21 and exposed to either standard environment or environmental enrichment. Mice in the standard enrichment group were shown to have impaired learning and memory at age P31 to P37 as assessed by the Morris water maze. Mice in the environmental enrichment group did not have impairment in learning or memory as compared to the control group, demonstrating that environmental enrichment is able to mitigate neurocognitive dysfunction caused by AIDN in an animal model.

\section{Desflurane}

Being one of the newest inhalational anesthetics used in clinical practice, it's not suprising that desflurane has the least amount of published data in regards to AIDN. In 2011 two animal studies were published on comparative neurotoxicity of desflurane, sevoflurane, and isoflurane, bringing into question whether inhalational anesthetics cause similar levels of neurodegeneration at equivalent MAC values.

The first comparison study exposed P7-8 mice to $6 \mathrm{~h}$ of $7.4 \%$ desflurane, $2.9 \%$ sevoflurane, or $1.5 \%$ isoflurane, which resulted in similar levels of AIDN as assessed immunohistochemically and by colorimetric caspase 3 assay [44]. A second study published later in the year had a very similar study design, where P6 mice were exposed to $6 \mathrm{~h}$ of $8 \%$ desflurane, 3\% sevoflurane, or $2 \%$ isoflurane, showing that $8 \%$ desflurane caused more neurodegeneration than $2 \%$ isoflurane, which caused more toxicity than $2 \%$ sevoflurane [18]. In the same study, behavioral testing showed that mice in the desflurane group had impaired working memory at week 6 of age as assessed by Y-maze, and impaired long term memory at week 7 of age as assessed by fear conditioning. The mice in the sevoflurane and isoflurane groups did not show impaired working memory, but did have impaired long term memory, which would further support the notion of desflurane being more neurotoxic than sevoflurane or isoflurane at equivalent MAC doses.

More studies need to be conducted to better determine if inhalational anesthetics have different neurotoxic profiles at equivalent MAC doses in animals, as current studies have conflicting results.

\section{Nitrous oxide}

Interestingly, nitrous oxide is the only inhalational anesthetic that has not caused AIDN in animal models when used as a sole anesthetic [45]. When P7 SpragueDawley rats were exposed to $50 \%, 100 \%$, or $150 \%$ (in a hyperbaric chamber) nitrous oxide for $6 \mathrm{~h}$, no significant increases in neuroapoptosis were noted $[3,6]$. However, $75 \%$ nitrous oxide added to $0.75 \%$ isoflurane worsened AIDN compared to isoflurane alone, suggesting that nitrous oxide does have an additive toxicity effect when combined with other anesthetic agents. Unlike xenon, pretreatment with nitrous oxide before an anesthetic exposure does not attenuate levels of neurodegeneration [22].

\section{Xenon}

Xenon is an interesting anesthetic gas in regards to animal studies and AIDN. The earliest animal study on xenon and AIDN showed that P7 Sprague-Dawley rats exposed to $75 \%$ xenon for $6 \mathrm{~h}$ did not have any significant increase in neurodegeneration, and that xenon when added to $0.75 \%$ isoflurane for $6 \mathrm{~h}$ attenuated AIDN in a dose dependent manner [46]. A repeat study, this time in P7 mice, again showed that xenon is able to decrease levels of AIDN when added to $0.75 \%$ isoflurane for $4 \mathrm{~h}$ [9]. However in the same study, $70 \%$ xenon for $4 \mathrm{~h}$ as a sole anesthetic caused significant increases in neurodegeneration, which raised the question of whether xenon was as benign as suggested by the prior study in P7 rats.

A study on hippocampal slice cultures from P7 rats concluded that xenon increased neuroapoptosis in a similar fashion to sevoflurane and isoflurane at equipotent concentrations [24]. Xenon at $0.75 \mathrm{MAC}$ (60\% at $1.2 \mathrm{~atm})$ for $6 \mathrm{~h}$ did not show any significant increase in AIDN. However, higher doses of xenon at 1 and 2 MAC (60\% at 2.67 or $3.67 \mathrm{~atm}$ ) for $6 \mathrm{~h}$ did show significant increases in neurodegeneration. Interestingly, pretreatment with $1.4 \%$ isoflurane $(0.75 \mathrm{MAC})$ for $2 \mathrm{~h}$, followed by a $6 \mathrm{~h}$ exposure to 1 MAC of either xenon, isoflurane, or sevoflurane $26 \mathrm{~h}$ after pretreatment, was associated with attenuation of AIDN compared to groups without pretreatment. In vivo studies are needed to confirm whether this pretreatment strategy is effective in live animals.

\section{Discussion}

In 2003 the results on AIDN published by JevtovicTodorovic et al [3] created much debate within the pediatric anesthesia community. After a decade of subsequent research, it is evident that in multiple differing mammalian species, exposure to anesthetic medications during a period of brain vulnerability (peak synaptogenesis) is associated with significant neurodegeneration and long term neurocognitive dysfunction that lasts into adulthood [3,6,9-13]. Of particular interest is the recent study comparing desflurane, sevoflurane, and isoflurane at equipotent MAC levels 
[18]. Further investigation into the specific mechanistic differences between these inhalational anesthetics may shed more light on AIDN and how it impairs working and long term memory in mice.

Out of all inhalational anesthetics reviewed, nitrous oxide was the only agent that did not cause AIDN when used as a sole anesthetic agent [3,6]. This key difference may be due to the fact that nitrous oxide exerts its primary effect through NMDA receptor antagonism, instead of $\mathrm{GABA}_{\mathrm{A}}$ receptor activation. In a similar fashion xenon works predominantly through NMDA receptor antagonism, but has been shown to cause significant increase in neurodegeneration when used as a sole anesthetic $[9,24]$. Cross comparison study of these two anesthetic agents may further our understanding of how anesthetic agents cause differing levels of AIDN even when they exert their function through the same primary receptor. More research needs to be conducted to determine the exact ramifications these findings should have on the clinical practice of pediatric anesthesiology.

To date there have only been a few observational studies done in humans, which have had mixed findings. A group of studies from the Mayo Clinic have shown that multiple anesthetic exposures in infants and children, but not a single exposure, increases the risk of learning disabilities as well as later development of attention-deficit/hyperactivity disorder [47-49]. Similar studies have demonstrated that a single exposure to general anesthesia causes increased risk of developmental disorders and deficits in language/abstract reasoning in children less than 3 years of age [50-52]. Other studies do not find any association between exposure of children to general anesthesia and the development of abnormal behavior or poor academic performance later on in life [53-55]. In addition, two studies on neonates report that exposure to prolonged sedation is not associated with increased risk of abnormal neurodevelopment [56,57].

The aforementioned human observational studies all used databases that were originally collected for purposes other than research on AIDN. Observational studies have significant limitations due to confounding variables, which make interpretation of these studies extremely complicated. The lack of prospective trials specifically focused on AIDN and the developing human brain makes it difficult to recommend if any changes should be made to the way anesthesia is currently practiced in infants and children.

\section{Conclusion}

At this time the anesthesia community is waiting for guidance from prospective trials such as the PANDA and GAS studies to show whether present clinical practices need to be altered. This is particularly critical, as many pediatric patients have undergone surgery and anesthesia with no apparent harm. Further it may be difficult to distinguish the effects of anesthesia on the developing brain from surgery-related effects that may follow the condition that mandated surgery or postoperative events such as inflammation, pain and any necessary drug treatments. Welldesigned prospective studies investigating AIDN in humans may take years to reach conclusions, thus it is prudent to continue research in animal models, particularly focusing on determining the specific mechanistic pathways that cause AIDN. Studies that identifiy mechanistic pathways resulting in AIDN may then provide insight into novel treatment modalities that can hinder or reverse causes of neurodegeneration.

\section{Abbreviations}

AIDN: Anesthesia-induced developmental neurotoxicity; NMDA: N-methyl-D-

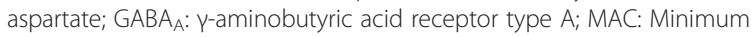
alveolar concentration.

\section{Competing interests}

The authors declare they have no competing interests.

\section{Authors' contributions}

MW designed the review, carried out the literature search, analyzed the included literature and drafted the manuscript. JZ helped in the design of the review, and critically edited the manuscript. RA analyzed the included literature and critically edited the manuscript. All authors read and approved the final manuscript.

\section{Acknowledgement}

This work was supported entirely by the Departments of Anesthesiology and Physiology, Loma Linda University School of Medicine, Loma Linda, CA.

\section{Author details}

${ }^{1}$ Department of Anesthesiology, Loma Linda University School of Medicine, Loma Linda, CA 92350, USA. '2Departments of Physiology, Neurosurgery, and Anesthesiology, Loma Linda University School of Medicine, Loma Linda, CA, USA.

Received: 30 September 2013 Accepted: 11 February 2014 Published: 14 February 2014

\section{References}

1. Sun LS, Li G, Dimaggio C, Byrne M, Rauh V, Brooks-Gunn J, Kakavouli A, Wood A, Coinvestigators of the Pediatric Anesthesia Neurodevelopment Assessment Research N: Anesthesia and neurodevelopment in children: time for an answer? Anesthesiology 2008, 109:757-761.

2. Ikonomidou C, Bittigau P, Ishimaru MJ, Wozniak DF, Koch C, Genz K, Price MT, Stefovska V, Horster F, Tenkova T, et al: Ethanol-induced apoptotic neurodegeneration and fetal alcohol syndrome. Science 2000, 287:1056-1060

3. Jevtovic-Todorovic V, Hartman RE, Izumi Y, Benshoff ND, Dikranian K, Zorumski CF, Olney JW, Wozniak DF: Early exposure to common anesthetic agents causes widespread neurodegeneration in the developing rat brain and persistent learning deficits. J Neurosci 2003, 23:876-882.

4. Anand KJ, Soriano SG: Anesthetic agents and the immature brain: are these toxic or therapeutic? Anesthesiology 2004, 101:527-530.

5. Wise-Faberowski L, Zhang H, Ing R, Pearlstein RD, Warner DS: Isoflurane-induced neuronal degeneration: an evaluation in organotypic hippocampal slice cultures. Anesth Analg 2005, 101:651-657. table of contents.

6. Yon JH, Daniel-Johnson J, Carter LB, Jevtovic-Todorovic V: Anesthesia induces neuronal cell death in the developing rat brain via the intrinsic and extrinsic apoptotic pathways. Neuroscience 2005, 135:815-827.

7. Mellon RD, Simone AF, Rappaport BA: Use of anesthetic agents in neonates and young children. Anesth Analg 2007, 104:509-520.

8. Sun LS, Li G, DiMaggio CJ, Byrne MW, Ing C, Miller TL, Bellinger DC, Han S, McGowan FX: Feasibility and pilot study of the Pediatric Anesthesia NeuroDevelopment Assessment (PANDA) project. J Neurosurg Anesthesiol 2012, 24:382-388. 
9. Cattano D, Williamson P, Fukui K, Avidan M, Evers AS, Olney JW, Young C: Potential of xenon to induce or to protect against neuroapoptosis in the developing mouse brain. Can J Anaesth 2008, 55:429-436.

10. Rizzi S, Carter LB, Ori C, Jevtovic-Todorovic V: Clinical anesthesia causes permanent damage to the fetal guinea pig brain. Brain Pathol 2008, 18:198-210.

11. Brambrink AM, Evers AS, Avidan MS, Farber NB, Smith DJ, Zhang X, Dissen GA, Creeley CE, Olney JW: Isoflurane-induced neuroapoptosis in the neonatal rhesus macaque brain. Anesthesiology 2010, 112:834-841.

12. Rizzi $S$, Ori $C$, Jevtovic-Todorovic V: Timing versus duration: determinants of anesthesia-induced developmental apoptosis in the young mammalian brain. Ann N Y Acad Sci 2010, 1199:43-51.

13. Zou X, Liu F, Zhang X, Patterson TA, Callicott R, Liu S, Hanig JP, Paule MG, Slikker W Jr, Wang C: Inhalation anesthetic-induced neuronal damage in the developing rhesus monkey. Neurotoxicol Teratol 2011, 33:592-597.

14. Hirota K, Roth SH, Fujimura J, Masuda A, Ito Y: GABAergic mechanisms in the action of general anesthetics. Toxicol Lett 1998, 100-101:203-207.

15. Solt K, Eger El 2nd, Raines DE: Differential modulation of human $\mathrm{N}$-methyl-D-aspartate receptors by structurally diverse general anesthetics. Anesth Analg 2006, 102:1407-1411.

16. Eger El 2nd, Johnson BH: MAC of I-653 in rats, including a test of the effect of body temperature and anesthetic duration. Anesth Analg 1987, 66:974-976.

17. Orliaguet $G$, Vivien B, Langeron $O$, Bouhemad B, Coriat $P$, Riou B: Minimum alveolar concentration of volatile anesthetics in rats during postnatal maturation. Anesthesiology 2001, 95:734-739.

18. Stratmann G, Sall JW, Eger El 2nd, Laster MJ, Bell JS, May LD, Eilers H, Krause M, Heusen F, Gonzalez HE: Increasing the duration of isoflurane anesthesia decreases the minimum alveolar anesthetic concentration in 7-day-old but not in 60-day-old rats. Anesth Analg 2009, 109:801-806.

19. Kodama M, Satoh Y, Otsubo Y, Araki Y, Yonamine R, Masui K, Kazama T: Neonatal desflurane exposure induces more robust neuroapoptosis than do isoflurane and sevoflurane and impairs working memory. Anesthesiology 2011, 115:979-991.

20. Gonsowski CT, Eger El 2nd: Nitrous oxide minimum alveolar anesthetic concentration in rats is greater than previously reported. Anesth Analg 1994, 79:710-712.

21. Dobbing J, Sands J: Comparative aspects of the brain growth spurt. Early Hum Dev 1979, 3:79-83.

22. Head BP, Patel HH, Niesman IR, Drummond JC, Roth DM, Patel PM: Inhibition of p75 neurotrophin receptor attenuates isoflurane-mediated neuronal apoptosis in the neonatal central nervous system. Anesthesiology 2009, 110:813-825.

23. Shu Y, Patel SM, Pac-Soo C, Fidalgo AR, Wan Y, Maze M, Ma D: Xenon pretreatment attenuates anesthetic-induced apoptosis in the developing brain in comparison with nitrous oxide and hypoxia. Anesthesiology 2010, 113:360-368.

24. Shu Y, Zhou Z, Wan Y, Sanders RD, Li M, Pac-Soo CK, Maze M, Ma D: Nociceptive stimuli enhance anesthetic-induced neuroapoptosis in the rat developing brain. Neurobiol Dis 2012, 45:743-750.

25. Loepke AW, Istaphanous GK, McAuliffe JJ 3rd, Miles L, Hughes EA, McCann JC, Harlow KE, Kurth CD, Williams MT, Vorhees CV, Danzer SC: The effects of neonatal isoflurane exposure in mice on brain cell viability, adult behavior, learning, and memory. Anesth Analg 2009, 108:90-104.

26. Brosnan $\mathrm{H}$, Bickler PE: Xenon neurotoxicity in rat hippocampal slice cultures is similar to isoflurane and sevoflurane. Anesthesiology 2013, 119:335-344.

27. Zhang $X$, Xue $Z$, Sun A: Subclinical concentration of sevoflurane potentiates neuronal apoptosis in the developing C57BL/6 mouse brain. Neurosci Lett 2008, 447:109-114

28. Satomoto M, Satoh Y, Terui K, Miyao H, Takishima K, Ito M, Imaki J: Neonatal exposure to sevoflurane induces abnormal social behaviors and deficits in fear conditioning in mice. Anesthesiology 2009, 110:628-637.

29. Liang G, Ward C, Peng J, Zhao Y, Huang B, Wei H: Isoflurane causes greater neurodegeneration than an equivalent exposure of sevoflurane in the developing brain of neonatal mice. Anesthesiology 2010, 112:1325-1334.

30. Constant I, Seeman R, Murat I: Sevoflurane and epileptiform EEG changes. Paediatr Anaesth 2005, 15:266-274.

31. Conreux F, Best O, Preckel MP, Lhopitault C, Beydon L, Pouplard F, Granry JC: Electroencephalographic effects of sevoflurane in pediatric anesthesia: a prospective study of 20 cases. Ann Fr Anesth Reanim 2001, 20:438-445
32. Vakkuri A, Yli-Hankala A, Sarkela M, Lindgren L, Mennander S, Korttila K, Saarnivaara $L$, Jantti V: Sevoflurane mask induction of anaesthesia is associated with epileptiform EEG in children. Acta Anaesthesio/ Scand 2001, 45:805-811.

33. Constant I, Dubois MC, Piat V, Moutard ML, McCue M, Murat I: Changes in electroencephalogram and autonomic cardiovascular activity during induction of anesthesia with sevoflurane compared with halothane in children. Anesthesiology 1999, 91:1604-1615.

34. Nieminen K, Westeren-Punnonen S, Kokki H, Ypparila H, Hyvarinen A, Partanen J: Sevoflurane anaesthesia in children after induction of anaesthesia with midazolam and thiopental does not cause epileptiform EEG. Br J Anaesth 2002, 89:853-856.

35. Edwards DA, Shah HP, Cao W, Gravenstein N, Seubert CN, Martynyuk AE: Bumetanide alleviates epileptogenic and neurotoxic effects of sevoflurane in neonatal rat brain. Anesthesiology 2010, 112:567-575.

36. Yonamine R, Satoh $Y$, Kodama M, Araki Y, Kazama T: Coadministration of hydrogen gas as part of the carrier gas mixture suppresses neuronal apoptosis and subsequent behavioral deficits caused by neonatal exposure to sevoflurane in mice. Anesthesiology 2013, 118:105-113.

37. Takeuchi S, Wada K, Nagatani K, Osada H, Otani N, Nawashiro H: Hydrogen may inhibit collagen-induced platelet aggregation: an ex vivo and in vivo study. Intern Med 2012, 51:1309-1313.

38. Ohta S: Molecular hydrogen is a novel antioxidant to efficiently reduce oxidative stress with potential for the improvement of mitochondrial diseases. Biochim Biophys Acta 1820, 2012:586-594.

39. Boscolo A, Starr JA, Sanchez V, Lunardi N, DiGruccio MR, Ori C, Erisir A, Trimmer P, Bennett J, Jevtovic-Todorovic V: The abolishment of anesthesia-induced cognitive impairment by timely protection of mitochondria in the developing rat brain: the importance of free oxygen radicals and mitochondrial integrity. Neurobiol Dis 2012, 45:1031-1041.

40. Hoffman AN, Malena RR, Westergom BP, Luthra P, Cheng JP, Aslam HA, Zafonte RD, Kline AE: Environmental enrichment-mediated functional improvement after experimental traumatic brain injury is contingent on task-specific neurobehavioral experience. Neurosci Lett 2008, 431:226-230.

41. Kline AE, Wagner AK, Westergom BP, Malena RR, Zafonte RD, Olsen AS, Sozda CN, Luthra P, Panda M, Cheng JP, Aslam HA: Acute treatment with the $5-\mathrm{HT}(1 \mathrm{~A})$ receptor agonist 8-OH-DPAT and chronic environmental enrichment confer neurobehavioral benefit after experimental brain trauma. Behav Brain Res 2007, 177:186-194.

42. Sozda CN, Hoffman AN, Olsen AS, Cheng JP, Zafonte RD, Kline AE: Empirical comparison of typical and atypical environmental enrichment paradigms on functional and histological outcome after experimental traumatic brain injury. J Neurotrauma 2010, 27:1047-1057.

43. Zheng H, Dong Y, Xu Z, Crosby G, Culley DJ, Zhang Y, Xie Z: Sevoflurane anesthesia in pregnant mice induces neurotoxicity in fetal and offspring mice. Anesthesiology 2013, 118:516-526.

44. Istaphanous GK, Howard J, Nan X, Hughes EA, McCann JC, McAuliffe JJ, Danzer SC, Loepke AW: Comparison of the neuroapoptotic properties of equipotent anesthetic concentrations of desflurane, isoflurane, or sevoflurane in neonatal mice. Anesthesiology 2011, 114:578-587.

45. Zou X, Sadovova N, Patterson TA, Divine RL, Hotchkiss CE, Ali SF, Hanig JP, Paule MG, Slikker W Jr, Wang C: The effects of L-carnitine on the combination of, inhalation anesthetic-induced developmental, neuronal apoptosis in the rat frontal cortex. Neuroscience 2008, 151:1053-1065.

46. Ma D, Williamson $P$, Januszewski $A$, Nogaro MC, Hossain M, Ong LP, Shu $Y$, Franks NP, Maze M: Xenon mitigates isoflurane-induced neuronal apoptosis in the developing rodent brain. Anesthesiology 2007, 106:746-753.

47. Wilder RT, Flick RP, Sprung J, Katusic SK, Barbaresi WJ, Mickelson C, Gleich SJ, Schroeder DR, Weaver AL, Warner DO: Early exposure to anesthesia and learning disabilities in a population-based birth cohort. Anesthesiology 2009, 110:796-804.

48. Sprung J, Flick RP, Katusic SK, Colligan RC, Barbaresi WJ, Bojanic K, Welch TL, Olson MD, Hanson AC, Schroeder DR, et al: Attention-deficit/hyperactivity disorder after early exposure to procedures requiring general anesthesia. Mayo Clin Proc 2012, 87:120-129.

49. Flick RP, Katusic SK, Colligan RC, Wilder RT, Voigt RG, Olson MD, Sprung J, Weaver AL, Schroeder DR, Warner DO: Cognitive and behavioral outcomes after early exposure to anesthesia and surgery. Pediatrics 2011, 128:e1053-e1061.

50. DiMaggio C, Sun LS, Kakavouli A, Byrne MW, Li G: A retrospective cohort study of the association of anesthesia and hernia repair surgery with behavioral and developmental disorders in young children. $J$ Neurosurg Anesthesiol 2009, 21:286-291. 
51. DiMaggio C, Sun $L S$, Li G: Early childhood exposure to anesthesia and risk of developmental and behavioral disorders in a sibling birth cohort. Anesth Analg 2011, 113:1143-1151.

52. Ing C, DiMaggio C, Whitehouse A, Hegarty MK, Brady J, von UngernSternberg BS, Davidson A, Wood AJ, Li G, Sun LS: Long-term differences in language and cognitive function after childhood exposure to anesthesia. Pediatrics 2012, 130:e476-e485.

53. Block RI, Thomas JJ, Bayman EO, Choi JY, Kimble KK, Todd MM: Are anesthesia and surgery during infancy associated with altered academic performance during childhood? Anesthesiology 2012, 117:494-503.

54. Hansen TG, Pedersen JK, Henneberg SW, Pedersen DA, Murray JC, Morton NS, Christensen K: Academic performance in adolescence after inguinal hernia repair in infancy: a nationwide cohort study. Anesthesiology 2011, 114:1076-1085.

55. Hansen TG, Pedersen JK, Henneberg SW, Morton NS, Christensen K: Educational outcome in adolescence following pyloric stenosis repair before 3 months of age: a nationwide cohort study. Paediatr Anaesth 2013, 23:883-890.

56. Guerra GG, Robertson CM, Alton GY, Joffe AR, Cave DA, Dinu IA, Creighton DE, Ross DB, Rebeyka IM, Western Canadian Complex Pediatric Therapies Followup G: Neurodevelopmental outcome following exposure to sedative and analgesic drugs for complex cardiac surgery in infancy. Paediatr Anaesth 2011, 21:932-941.

57. Roze JC, Denizot S, Carbajal R, Ancel PY, Kaminski M, Arnaud C, Truffert P, Marret S, Matis J, Thiriez G, et al: Prolonged sedation and/or analgesia and 5-year neurodevelopment outcome in very preterm infants: results from the EPIPAGE cohort. Arch Pediatr Adolesc Med 2008, 162:728-733.

doi:10.1186/2045-9912-4-2

Cite this article as: Wang et al:: Adverse effect of inhalational anesthetics on the developing brain. Medical Gas Research 2014 4:2.

\section{Submit your next manuscript to BioMed Central and take full advantage of:}

- Convenient online submission

- Thorough peer review

- No space constraints or color figure charges

- Immediate publication on acceptance

- Inclusion in PubMed, CAS, Scopus and Google Scholar

- Research which is freely available for redistribution 